\title{
EFEITO DO FUNGO METARHIZIUM ANISOPLIAE (METSCH.) SOROK. (DEUTEROMYCETES) PARA ASTYANAX SCABRIPINNIS (JENYNS, 1842) (PISCES: CHARACIDAE)
}

\section{L.F.A. Alves ${ }^{1 *}$, S.B. Alves ${ }^{2 * *}$, L.G. Oliveira ${ }^{1 *}$, C.M. Jonsson ${ }^{3}$}

${ }^{1}$ Universidade Estadual do Oeste do Paraná, Centro de Ciências Biológicas e Saúde, Laboratório de Zoologia de Invertebrados, Rua Universitária, 2069, CEP 85819-110, Cascavel, PR, Brasil. E-mail: Ifaalves@unioeste.br

\section{RESUMO}

Avaliou-se o efeito de Metarhizium anisopliae (Metsch.) paraAstyanax scabripinnis (Jenyns, 1842) (Pisces, Characidae), em condições de laboratório. Suspensões aquosas de conídios recémproduzidos, viáveis (viabilidade mínima $90 \%)$ e inviabilizados por meio de autoclavagem $\left(121^{\circ} \mathrm{C}\right.$, 20 minutos, a $1 \mathrm{~atm}$ ), na concentração de $6,5 \times 10^{10}$ conídios/aquário (equivalente a $5 \times 10^{15}$ conídios/ ha, que representa 1.000 vezes a concentração recomendada para o controle de cigarrinhas de pastagens, principal praga-alvo deste entomopatógeno no Brasil), foram aplicadas em aquários contendo A. scabripinnis. Foram analisadas amostras de água e dos peixes, dos quais foram dissecados as brânquias e o estômago, em diferentes intervalos de tempo, a fim de se avaliar a presença dos conídios. Observaram-se diariamente o comportamento e a mortalidade de peixes em ambos os tratamentos. Avaliou-se nos peixes sobreviventes a morfologia das células das brânquias e do fígado. Verificou-se que nas brânquias não houve alteração no número de conídios ao longo de 16 dias de contato, sendo que no estômago houve um ligeiro acréscimo inicial seguido de redução constante. A viabilidade dos conídios em todos os locais avaliados decresceu após 24 horas da aplicação. Constatou-se que não houve morte ou quaisquer alterações comportamentais após 30 dias de contato, indicando a ausência de efeitos adversos associados à capacidade do fungo em provocar infecção ou exercer efeitos tóxicos em ambos os organismos-teste.

PALAVRAS-CHAVE: Organismosnão-alvo, entomopatógeno, avaliação derisco, controlebiológico.

\section{ABSTRACT}

EEFFECT OF THE FUNGUS METARHIZIUM ANISOPLIAE (METSCH.) SOROK. (DEUTEROMYCETES) ON ASTYANAX SCABRIPINNIS (JENYNS) (PISCES: CHARACIDAE). The effect of Metarhizium anisopliae (Metsch.) Sorokin on Astyanax scabripinnis (Jenyns, 1842) (Pisces, Characidae) under laboratory conditions was evaluated. Aqueous conidial suspensions either with a minimum viability of $90 \%$ or containing conidia rendered unviable by autoclaving were applied in fish tanks containing A. scabripinnis, at the concentration of $6.5 \times 10^{10}$ conidia/fish tank (equivalent to $5 \times 10^{15}$ conidia/ha, which represents 1000 times the recommended concentration for the control of pasture spittlebugs, the main target pest of this entomopathogen in Brazil). Water and fish samples were analyzed; the fish gills and stomachs were dissected at different time intervals to evaluate the presence of conidia. Fish behavior and mortality were observed daily in both treatments. The morphology of gill and liver cells was evaluated in the surviving fish. No changes in the number of conidia were verified in the gills throughout 16 days of contact; in the stomach, there was a slight initial increase followed by a steady reduction. Conidial viability decreased in all places evaluated 24 hours after application. No fish death or any behavioral alterations occurred after 30 days of contact, indicating the absence of adverse effects associated with the entomopathogen on the test organisms. The absence of signs of infectivity and other adverse effects are a further indication in favor of the use of M. anisopliae as a biopesticide.

KEY WORDS: Nontarget organisms, entomopathogen, risk assessment, biological control.

\footnotetext{
${ }^{2}$ Escola Superior de Agricultura “Luiz de Queiroz”, Departamento de Entomologia, Zoologia Agrícola, Piracicaba, SP, Brasil. In memoriam.

${ }^{3}$ EMBRAPA Meio Ambiente, Jaguariúna, SP, Brasil.

*Programa de Pós-graduação em Engenharia Agrícola, nível Mestrado.

**Bolsista de Produtividade em Pesquisa, CNPq.
} 


\section{INTRODUÇÃO}

Um dos maiores desafios da agricultura moderna é o aumento da produção agrícola sem o comprometimento da qualidade de seus produtos, bem como do solo e dos recursos hídricos, sem reduzir a diversidade de plantas, animais e microrganismos (JONSSON; MAIA, 1999).

Os insetos e ácaros estão entre os principais problemas que afetam a produção agrícola, causando danos diretos e indiretos. Considerando que o controle dessas pragas é essencial e o uso de agrotóxicos na agricultura moderna é, em muitos casos, imprescindível, quando empregados de forma inadequada são responsáveis por problemas relativos à saúde e danos ao ambiente. Como alternativa aos agrotóxicos, outras possibilidades vêm sendo estudadas, incluindo-se o uso de inimigos naturais, principalmente os microrganismos entomopatogênicos, que também não devem ser utilizados indiscriminadamente, mas seguindo princípios ecológicos (JONSSON; MAIA, 1999).

De acordo com Alves et al. (1998), o faturamento com biodefensivos representa apenas $1 \%$ do mercado mundial de agrotóxicos. No entanto, alguns setores, como da cana-de-açúcar, citricultura, pecuária e agricultura orgânica, vêm utilizando produtos biológicos para o controle de pragas, sendo para este último uma das principais estratégias de controle.

O uso crescente de tais agentes de pragas desperta preocupações na sociedade sobre sua real segurança em relação ao homem e ao ambiente, havendo certa razãoemnão seconsiderarseguroum produto, apenas pela indicação de se tratar de origem biológica, sendo necessário comprovar-se tal inocuidade, por meio da análise de risco (Pereira et al., 1998).

JONSSON; MAIA (1999) relataram que a análise de risco é um item previsto no processo de registro de pesticidas para uso comercial. No Brasil, especificamente em relação aos entomopatógenos, praticamente não existem estudos realizados nesta área, notadamente sobre espécies nativas de peixes, como é o caso deAstyanax scabripinnis (Jenyns, 1842) (Pisces, Characidae). Também, em outros países, poucos trabalhos foram realizados com espécies de animais consideradas não-alvo. Da mesma forma , WINKALER et al. (1990) ressaltaram que o efeito de diferentes contaminantes pode se manifestar em vários níveis de organização biológica dos peixes, como disfunções fisiológicas, alterações estruturais em órgãos e tecidos e modificações comportamentais (WINKALERetal., 1990).

Atualmente, os pesquisadores estão preocupados em efetuar uma análise rigorosa da segurança dos agentes de controle microbiano, notadamente aqueles que, como os fungos possuem grande capacidade de esporulação, disseminação e sobrevivência no ambiente, sendo capazes de infectar outros organismos do agroecossistema (Jonsson; MAIA, 1999).

Com relação a Metarhizium anisopliae e ao peixe $A$. scabripinnis, existem duas possibilidades de contato. Na primeira, o fungo utilizado para o controle de pragas agrícolas poderia ser levado para lagos e rios por meio daágua da chuva e da irrigação. Na segunda possibilidade, o fungo seria utilizado para o controle de mosquitos.

Assim, este trabalho teve por objetivo avaliar o risco do fungo $M$. anisopliae para o lambari, $A$. scabripinnis, organismo não-alvo das aplicações deste fungo em campo.

\section{MATERIAL E MÉTODOS}

O trabalho foi realizado com base no Protocolo para Avaliação de Agentes Microbianos de Controle de Pragas e Registro com Biopesticidas, proposto por JonsSON; MaIA (1999).

Para tal, utilizou-se o isolado E9 do fungo $M$. anisopliae, proveniente do Banco de Entomopatógenos do Setor de Patologia de Insetos (Departamento de Entomologia, Fitopatologia e Zoologia Agrícola/ ESALQ/USP), obtido originalmente de adultos de cigarrinhas das pastagensMahanarva posticata (Stal).

A partir do inóculo original armazenadoem freezer $\left(-10^{\circ} \mathrm{C}\right)$, o fungo foi multiplicado em placas de Petri contendo meio de cultura (BDA), incubadas em câmara de B.O.D. ( $25 \pm 1^{\circ} \mathrm{C}, 14 \mathrm{~h}$ de fotofase), durante sete dias. Em seguida, o fungo foi produzido em maior quantidade, em arroz pré-cozido, conforme o método Biomax $^{\circledR}$ (Alves; Pereira, 1998).

Após o período de crescimento e conidiogênese, procedeu-se a separação dos conídios que foram armazenados em freezer $\left(-10^{\circ} \mathrm{C}\right)$ até a sua utilização. Foram utilizados conídios com viabilidade superior a $90 \%$.

Para a inativação do fungo, preparou-se uma suspensão de conídios em água destilada + espalhante adesivo $0,01 \%$, que foi autoclavada a $121^{\circ} \mathrm{C}$, durante 20 minutos, a 1 atm Previamente à sua utilização, procedeu-se a análise da viabilidade dos conídios em meio decultura a fim de se comprovar a sua inativação.

O peixe utilizado foi o lambari (A. scabripinnis), fornecido pelo Centro de Pesquisas em Aqüicultura Ambiental (CPAA), Toledo, PR, com comprimento médio de $3 \mathrm{~cm}$ e massa corpórea média de 2,5 g.

Após a coleta, os peixes foram mantidos em aquários de vidro com $35 \mathrm{~L}(36 \mathrm{~cm} \times 36 \mathrm{~cm} \times 35 \mathrm{~cm}-$ comprimento $\mathrm{x}$ largura $\mathrm{x}$ altura) e preenchidos com água tratada, desclorada com solução de tiossulfato de sódio $12 \%$, com temperatura de $25 \pm 2^{\circ} \mathrm{C}$. Os aquários foram dispostos em uma bancada, mantidos em uma sala climatizada a $28^{\circ} \mathrm{Ce}$ com $14 \mathrm{~h}$ de fotofase. 
Os peixes foram alimentados duas vezes ao dia com ração apropriada para a espécie (40\% de proteína bruta), sendo as condições descritas utilizadas para a condução de todos os experimentos.

Presença e quantificação de $M$. anisopliae nas brânquias e no estômago de $A$. scabripinnis

O experimento constou de dois tratamentos: um com aquários tratados com suspensão de conídios viáveis de $M$. anisopliae e outro grupo tratado com uma suspensão de conídios de M. anisopliae inativo, na concentração de $6,5 \times 10^{10}$ conídios/aquário, em ambos os casos. Essa concentração corresponde a $5 \times 10^{15}$ conídios/ha, que representa 1.000 vezes a concentração recomendada para o controle de cigarrinhas de pastagens em condições de campo (Alves, 1998). Um terceiro grupo de peixes não expostos ao fungo foi considerado como testemunha. Para cada um deles foram destinadas três repetições, cada uma com um aquário contendo sete peixes, respeitando-se a relação de $1 \mathrm{~g}$ de massa corpórea de peixe por litro de água.

Os peixes foram mantidos nos aquários durante 16 dias em sistema semiestático, com troca deaproximadamente $10 \%$ da água coletada no fundo dos aquários, a cada dois dias para limpeza do excesso de alimento e fezes em decomposição, repondo-se a água em seguida.

Periodicamente, foram coletados peixes dos aquários, sendo retirado um peixe de cada repetição dos recipientes tratados com fungo e da testemunha, logo após a aplicação e depois de 12 horas e 1, 2, 4, 8 e 16 dias. Os peixes coletados foram sacrificados por meio de secção medular e, em seguida, retiraram-se dos peixes as brânquias e o estômago, por meio de cortes na região lateral do corpo e do abdome.

Os órgãos foram transferidos para tubos de ensaio contendo $3 \mathrm{~mL}$ deágua destilada + espalhante adesivo $0,01 \%$ e, em seguida, foram homogeneizados com um micro-triturador elétrico. Amostras destas suspensões foram diluídas e submetidas à contagem em câmara de Neubauer e o resultado foi expresso em número de conídios/órgão.

Viabilidade de M. anisopliae nas brânquias e no estômago de A. scabripinnis e na água do aquário

Amostras de 0,1 mL do homogeneizado dos órgãos foram também inoculadas em placas de Petri contendo meio de cultura ME + tetraciclina, as quais foram incubadas durante $20 \mathrm{~h}$ em câmara B.O.D. (25 $\pm 1^{\circ} \mathrm{C}, 14 \mathrm{~h}$ de fotofase). Para avaliação da viabilidade do fungo na água, foram tomadas três amostras de $3 \mathrm{~mL}$ da água de cada aquário. Após a homogeneização, 0,1 mL de cada suspensão foi transferido de cada amostra para placas com meio de cultura. Tanto para os órgãos como para a água dos aquários foram preparadas três placas para cada repetição, totalizando nove placas para cada tratamento.

Após o período de incubação, foi determinada a porcentagem de conídios viáveis, observando-se as placas em microscópio de luz (aumento 400 x). O resultado foi expresso em números de conídios viáveis e não viáveis.

Os dados obtidos em ambos os experimentos foram analisados estatisticamente quanto à variância (teste F). As médias foram comparadas entre si pelo teste de Tukey $(\mathrm{P}<0,05)$, seguindo o delineamento experimental inteiramente aleatorizado em esquema fatorial, buscando-se verificar a interação do tempo na quantidade de conídios nos órgãos ou na na água dos aquários, utilizando o programa estatístico SISVAR (FERREIRA, 2003).

Ação de M. anisopliae na sobrevivência e alterações comportamentais de A. scabripinnis

Seguindo o mesmo procedimento experimental descrito no experimento 1, foram preparadas eaplicadas suspensões de conídios viáveis e não viáveis de M. anisopliae, além de água destilada + espalhante adesivo $0,01 \%$ correspondente à testemunha.

Como descrito anteriormente, os aquários tiveram seu conteúdo renovado em $10 \%$ a cada dois dias, retirando o excesso dealimentos e de fezes decantados no seu fundo repondo-seigual volume deágua. No15응 dia após o início do experimento, houve a troca total da água dos aquários, quando o fungo foi novamente reaplicado, na mesma concentração inicial.

Para cada um dos tratamentos foram utilizadas cinco repetições, que consistiram cada uma delas de um aquário contendo cinco peixes, sendo que os aquários foram mantidos nas mesmas condições igualmente descritas.

Diariamente, no período da manhã, observaramseatentamente os peixes durante 2 minutos/aquário, durante 30 dias, quanto à ocorrência de eventual mortalidade, alterações comportamentais ou a presença de sinais de infecção.

Com relação ao comportamento dos animais, observou-se eventual perda de equilíbrio ou natação errática na coluna d'água, peixes saltando constantemente, batimentos operculares acelerados concentração dos peixes na superfície da água. Da mesma forma, verificou-se o surgimento de doença que pudesse ser iniciada pelo efeito estressante do fungo. Em seguida, atribuiu-se sinal negativo (-) para a ausência de anormalidade e positivo (+) para qualquer alteração.

Alteração morfológica das células das branquiais e do fígado de A. scabripinnis 
Ao final do teste anterior, foram coletados cinco peixes, de cada um dos três tratamentos, que foram sacrificados por secção medular e as brânquias foram dissecadas e fixadas individualmente em solução de Bouin por 6 horas. Em seguida, foram transferidas para frascos contento álcool $70 \%$ para conservação até sua utilização. Posteriormente, foram desidratadas por um processodeimersãoemsoluçãodeálcooletílicoemuma série crescente de concentração e, então, diafanizadas em xilol e, finalmente incluídas em parafina. Os blocos foram submetidos a cortes transversais com $7 \mu \mathrm{m}$ de espessura em micrótomo. No caso das brânquias, os cortes foram seriados, ou seja, cortes do primeiro ao último arco branquial. Para o fígado, os cortes foram realizados na sua regiãocentral. Em seguida, o material foi disposto em lâminas e submetido à coloração por hematoxilina/eosina (HE) (WINKALER et al., 2001).

Posteriormente, o material foi observado em microscópio de luz (aumento de 400 e 1.000 x) para comparação do tamanho das células em função dos tratamentos aos quais os peixes foram submetidos. Para tal, escolheu-se aleatoriamente uma lâmina de cada corte por indivíduo, na qual foram mensuradas 20 áreas celulares utilizando-se lente ocular graduada, totalizando 100 medidas por tratamento.

\section{RESULTADOS E DISCUSSÃO}

Presença e quantificação de $M$. anisopliae nas brânquias e estômago de A. scabripinnis.

Verificou-se, em todas as avaliações, a presença de conídios não germinados nas brânquias e no estômago dos peixes (Tabela 1). Segundo Alves (1998), para a produção do tubo germinativo, o fungo deve encontrar condições favoráveis referentes à umidade, temperatura, pH, oxigênio e nutrição, não ocorrendo, provavelmente, alguma dessas condições no organismo testado.

Durante o período de avaliação, observou-se alteração no número de conídios nas brânquias ao longo do tempo, elevando-se após 12 horas da aplicação, mantendo-se estável durante 48 horas e, em seguida, reduzindo significativamente após 4 dias e, novamente na última avaliação.

De acordo com Jobling (1996), as brânquias, ao desempenharem sua função de respiração, permitem que passem pelos arcos branquiais, além de gases dissolvidos na água, matéria orgânica e microrganismos dispersos na coluna d'água, sendo absorvidas apenas moléculas de oxigênio livres na água. As partículas que se fixam nas brânquias são gradativamente liberadas pelos batimentos operculares que provocam o fluxo de água por entre a brânquia, justificando a presença de conídios neste órgão e sua redução ao longo do tempo.
Da mesma forma que nas brânquias, no estômago observou-se também diferença significativa no número de conídios em seu interior, sendo que entrea primeira e a segunda avaliação houve significativa elevação. Além disso, a maior média obtida ocorreu na segunda avaliação, decrescendo gradativamente nas demais, observando-se na última avaliação apenas $10 \%$ do valor máximo encontrado na segunda avaliação.

A elevação do número de conídios em ambos os órgãos, da primeira para a segunda avaliação, pode estar relacionada também à dispersão inicial do fungo na água logo após a sua aplicação, permitindo que esses conídios tenham sido absorvidos pelo peixe no momento da ingestão de alimento.

Verificou-se, porém, que os conídios não permaneceram suspensos na coluna d'água. Decorridas 24 horas da aplicação, os conídios formaram uma massa no fundo do aquário, indicando uma possível redução docontato dofungo com o peixe, explicandoa redução, pois o peixe não tem hábito de se alimentar revolvendo ofundo, sendo uma espécie predadora eque busca seu alimento na coluna d'água (EsPíritoSANTO etal., 2007).

Comparando-se ainda a ocorrência de conídios entre os dois órgãos em cada tempo, notou-se que houve diferença significativa em todas as avaliações, sendo sempre maior a concentração de conídios no estômago. Na avaliação inicial, a concentração no estômago foi 57 vezes maior em relação às brânquias e no decorrer das outras avaliações esta relação variou entre 40 e 100 vezes.

Resultados de ocorrência do fungo em órgãos de outros peixes também foram relatados por CASTRO et al. (2001), que analisaram homogeneizados de tecidos de Hyphessobrycon scholzei (Characidae) mantido em aquários de8 L por30 diascomofungo Trichodermastromaticum, aplicadoemsuspensãonaágua, observandoqueofungo permaneceu viável no organismo dos peixes.

Também Middaugh; Genthner (1994) avaliaram o efeito de Beauveria bassiana sobre ovos e embriões de Menidia beryllina (Atherinopsidae), mantidos em tubos de ensaio com a concentração de fungo T. stromaticum, variando entre $10^{3} \mathrm{e} 10^{6}$ conídios/ $\mathrm{mL}$, por um período de nove dias. $\mathrm{O}$ entomopatógeno se concentrou na superfíciedocórion doovoena mandíbula doembrião, não sendo mencionados outros efeitos.

Viabilidade de M. anisopliae nas brânquias e no estômago de $A$. scabripinnis e na água do aquário

Os conídios de M. anisopliae permaneceram viáveis, independente dolocal edo tempodeamostragem, com reduções gradativas entre as avaliações realizadas ao longo do tempo. Contudo, comparando a viabilidade dos conídios presentes tanto nos órgãos como na água, verificou-se que não houve diferença significativa nesse parâmetro (Tabela 2). 
Efeito do fungo Metarhizium anisopliae (Metsch.) Sorok.

(Deuteromycetes) para Astyanax scabripinnis (Jenyns, 1842) (Pisces: Characidae).
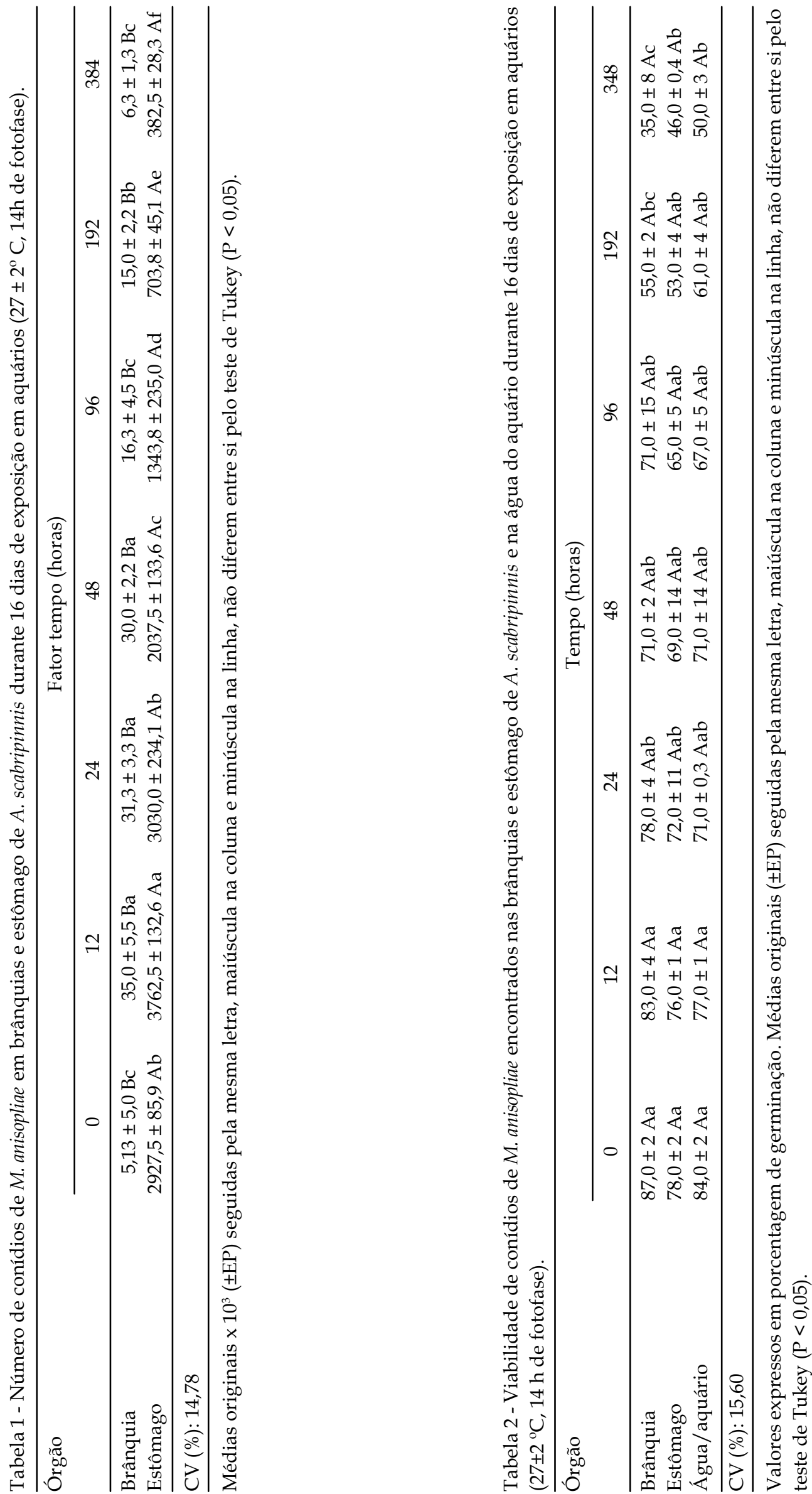
A viabilidade decresceu ao longo do tempo de maneira semelhante nos dois órgãos estudados e na água dos aquários, até a quinta avaliação (96 horas), quando a redução foi de aproximadamente $20 \%$ em relação à viabilidade original. A partir desta, a viabilidade decresceu em maior intensidadenas brânquias chegando a $35 \%$ de conídios viáveis.

Embora o estudo tenha sido realizado em camarões, GENTHNERet al. (1994) verificaram que o fungo $B$. bassiana inoculado por meio de injeções diretamente nos tecidos permaneceu viável após sete dias de exposição. O fungo germinou e cresceu, sendo observado em diversos tecidos e órgãos, incluindo o hepatopâncreas, tecidos musculares e brânquias.

Alves; LeCuONa (1998) relataram que M. anisopliae pode permanecer viável emágua de fonte por 72 horas eemágua esterilizada por 48 horas, sendo que a partir desse período a viabilidade decresce, sendo totalmente inibida em, aproximadamente 15 dias, diferindo dos resultados obtidos neste trabalho.

Ação de M. anisopliae na sobrevivência e alterações comportamentais de $A$. scabripinnis

Houve sobrevivência de $100 \%$ dos peixes nos três tratamentos realizados, evidenciando a ausência de toxicidade e patogenicidade de $M$. anisopliae para $A$. scabripinnis, mesmo em concentrações elevadas e por tempo prolongado, ainda que os conídios presentes estivessem viáveis em alguns órgãos do peixe.

Além disso, no transcorrer do período de avaliação, não foram observadas anormalidades comportamentais nos peixes que pudessem ser relacionadas à ação do fungo. Os peixes se mantiveram por todo o período do experimento sem evidências aparentes de estresse, mesmo quando passavam por um processo de troca parcial e/ou total da água.

Também, ausência de alterações no padrão normal de comportamento de $H$. scholzei foi observada por CAstro et al. (2001), depois da exposição desse peixe a T. stromaticum, por 30 dias. Tal como no presente estudo, os autores também constataram que, mesmo não ocorrendo efeitos deletérios sobre os peixes, o fungo permaneceu viável nos tecidos dos peixes.

O fato de nenhum peixe ter morrido após o contato com o fungo pode evidenciar a ausência de efeitos negativos, mesmo estando constantemente em contato com o entomopatógeno em concentrações 1.000 vezes maior àquela utilizada em campo. Esse resultado pode representar uma grande seletividade desse entomopatógeno ao vertebrado utilizado no teste.

Segundo Pereira etal. (1998), a maioria dos microrganismos utilizada no controle microbiano é muito segura do ponto de vista ambiental, devido principal- mente à grande diferença existente entre a fisiologia dos insetos e de outros animais, notadamente os vertebrados. Esses autores também mencionaram que outra barreira importante na prevenção do crescimento nos organismos não-alvos é o sistema imunológico desses animais. Embora insetos também possuam um sistema imunológico complexo, o sistema dos vertebrados, em geral, é mais sofisticado e eficiente. Durante a evolução dos fungos, os sistemas enzimáticos, toxinas e modo de crescimento se adaptaram para afetar certos mecanismos apresentados pelos insetos. No entanto, muitos desses elementos são bastante diferentes dos vertebrados, tornando o microrganismoineficiente ou totalmenteinócuo quando encontrado no corpo de um vertebrado, ou mesmo em outros invertebrados.

Confirmando tais hipóteses, KERWIN et al. (1988), estudando o efeito da exposição da truta arco-íris (Oncorhynchus mykiss Walbaum) ao fungo Lagenidium giganteum, observaram que não houve uma resposta significativa quanto à mortalidade entre os tratamentos e nem a ocorrência de efeitos adversos na sua saúde por vinte e um dias de experimento. Os autores ainda ressaltaram que apenas $4 \%$ dos 230 indivíduos testados morreram, não havendo evidências morfológicas da proliferação do fungo dentro dos peixes mortos. Também GentHner; MidDAugh (1995), expondo $M$. beryllina e embriões do camarão Palaemonetes pugio (Palaemonidae) ao fungo Colletotrichum gloeosporioides f. sp.aeschynomene, relataram a ausência de patogenicidade e toxicidade desse entomopa-tógeno para esses animais.

Corroborando esses estudos, JONSSON; GENTHNER (1997), além de exporem embriões do camarãoP.pugio a uma suspensão de conídios de C. gloeosporioides, também testaram o filtrado de meio de cultura e o extrato orgânico seco do fungo com a finalidade de avaliar a toxicidade aguda ao microcrustáceo Artemia salina. Os resultados demonstraram a ausência de efeitos adversos associados à capacidade do fungo em provocar infecção ou exercer efeitos tóxicos em ambos os organismos-teste.

No entanto, resultados diferentes também foram observados por Genthner; Middaugh (1992) e MidDAUGH; GENTHNER (1994), os quais mostraram que B. bassiana pode causar efeitos adversos em animais não pertencentes à classe Insecta. Estes pesquisadores adaptaram uma técnica de avaliação da toxicidade e teratogenicidade para averiguar o potencial do fungo em causar efeitos adversos no desenvolvimento embrionário do peixe $M$. beryllina. Dentre os efeitos observados, houve a ruptura do córion, defeitos de desenvolvimentoe mortes. Damesma forma,GENTHNER; Middaugh (1995) também observaram vários efeitos adversos como comprometimento cardíaco, ruptura do córion, anormalidades esqueléticas e expressão 
teratogênica após a exposição de embriões e larvas do peixe $M$. beryllina ao fungo entomopatogênico $M$. anisopliae.

Estes relatos sugerem que deva ser considerada a possibilidade de que, mesmo não ocorrendo mortalidade em uma determinada fase da vida do indivíduo testado, ainda possa ocorrer efeito negativo em outros estágios da vida deste, principalmente nas fases embrionária e larval.

Reforçando esta hipótese, GENTHNER et al. (1994), avaliando o efeito de conídios de $B$. bassiana sobre diferentes fases do desenvolvimento do camarão $P$. pugio, relataram que nos embriões e larvas do camarão o fungo, em exposição oral, não causou mortalidade. Contudo, quando injeções com conídios foram administradas aos adultos, ocorreram infecções, sendo observado crescimento do fungo em inúmeros tecidos e órgãos, incluindo o hepatopâncreas, tecido muscular e brânquias do animal. Desta forma, devese considerar o efeito que a forma de exposição do organismo não-alvo ao entomopatógeno pode ter na possibilidade do biopesticida apresentar-se ou não, tóxico ou patogênico.

Especificamente, em relação ao ser humano, Pereira et al. (1998) consideram pouco provável que os fungos entomopatogênicos sejam patogênicos ao ser humano, sendo mais comum relatos de reações alérgicas pelo contato com os fungos entomopatogênicos.

O primeiro caso de infecção em seres humanos por Beauveria spp. foi registrado na Alemanha, no qual verificou-se a infecção dos pulmões (alveolite), fígado e baço em uma mulher imunodeprimida (HENKE et al., 2002).

Da mesma forma, REVANKAR et al. (1999), além de citarem casos de infecção em seres humanos na Colômbia e Austrália, descrevem um estudo de caso inédito, isolando M. anisopliae de pacientes imunocompetentes nos EUA acometidos por sinusitefúngica. Os autores não conseguiram estabelecer qualquer relação com uso de tal agente de controle ea incidência nos pacientes.

Mais recentemente, OsóRIo et al. (2007) reportaram um estudo de caso ocorrido na Espanha com um paciente imunodeprimido que apresentou infecção cutânea causada por M. anisopliae, recomendando que este fungo seja considerado como um microrganismo com potencial para causar infecções em pacientes nestas condições.

Outro fator a ser considerado, do contato entre organismos não-alvo e entomopatógenos, foi também discutido por BRAZNER; ANDERSON (1986), após a realização de experimentos de ingestão de Bacillus thuringiensis por crustáceos. Os autores consideram que as aplicações de agentes microbianos de controle em campo não necessariamente podem trazer riscos toxicológicos para organismos localmente expostos, que também poderiam atuar como agentes de transporte para áreas não tratadas, expandindo a eficácia quanto ao controle biológico e ao número de organismos potencialmente expostos, sejam alvos ou nãoalvos.

Da mesma forma, vírus entomopatogênicos foram isolados das fezes de camundongos, ratos, coelhos, pássaros, peixes e insetos predadores, após terem sido ingeridos, o que sugere que esses animais também possam disseminar esses microrganismos na natureza SHADDUCK et al., 1980; SEgEL; SHADDUCK, 1990; Pereira et al., 1998; Oliveira et al., 2001).

Contudo, esta hipótese não foi ainda confirmada para os fungos entomopatogênicos, porém, pode-se considerar que existe a possibilidade de $A$.scabripinnis contribuir de maneira importante no transporte e disseminação de $M$. anisopliae, desde que o fungo consiga passar ileso pelo trato intestinal do peixe sendoliberadojunto às fezes dos indivíduos e permaneça ativo aos organismos-alvo no ambiente. Esse fato teria importância no controle de mosquitos transmissores de doenças para o homem, já que esse fungo é um bom controlador desses insetos.

\section{Alteração morfológica das células das branquiais e do fígado de A. scabripinnis}

A análise qualitativa das células das lamelas branquiais e das células do fígado revelou a ausência de variações significativas na área das células dos peixes provenientes, tanto dos aquários tratados como da testemunha, sendo que a área das células das brânquias foi de, aproximadamente, $19 \mu^{2} \mathrm{~m}^{2}$ no caso do fígado, o maior valor de área celular foi de, aproximadamente, $120 \mu \mathrm{m}^{2}$.

A relação de semelhança entre os tratamentos pode estar relacionada ao mecanismo de defesa dos peixes, uma vez que a produção e a liberação de muco nas brânquias fazem parte do mecanismo de defesa dos peixes (Fernandes; PernA-Martins, 2001). O muco contém substâncias inibidoras para o crescimento e estabelecimento de diversos parasitas em sua superfície externa, e para proliferação de bactérias e fungos existentes na água, podendo ter influenciado o efeito dos tratamentos inativo e ativo, mesmo o fungo não sendo encontrado normalmente no ambiente aquático. Mas pouco ainda se sabe sobre este efeito. RomANO; Cueva (1988) ressaltaram que as células de muco apresentam hiperplasia na presença de agentes de risco, como ectoparasitas presentes na água, passando a produzir uma proteção mucosa que, por outro lado, se produzida em excesso, pode acarretar uma impermeabilização dos filamentos branquiais, impedindo a respiração e até a morte dos peixes, o que não foi observado no presente estudo. 


\section{AGRADECIMENTOS}

Ao Conselho Nacional de Desenvolvimento Científico e Tecnológico pela concessão da bolsa de Mestrado e de Produtividade em Pesquisa, à CAPES pelo suporte financeiro para a realização dos experimentos, ao Núcleo de Estudos Interdisciplinares pela cessão do Laboratório de Biologia para a realização dos experimentos e aos estagiários do Laboratório de Zoologia de Invertebrados/CCBS, Unioeste, pelo auxílio nas atividades.

\section{REFERÊNCIAS}

ALVES, S.B. Fungos entomopatogênicos. In: ALVES, S.B. (Ed.). Controle microbiano de insetos. 2.ed. Piracicaba: FEALQ, 1998. p.289-371.

ALVES, S.B.; LECUONA, R.E. Epizootia aplicada ao controle microbiano de insetos. In: ALVES, S.B. (Ed.). Controle microbiano de insetos. 2.ed. Piracicaba: FEALQ, 1998. p.1143-1163.

ALVES, S.B.; MOINO JUNIOR, A.; ALMEIDA, J.E.M. Desenvolvimento, potencial de uso e comercialização de produtos microbianos. In: ALVES, S.B. (Ed.). Controle microbiano de insetos. 2.ed. Piracicaba: FEALQ, 1998. p.1143-1163.

ALVES, S.B.; PEREIRA, R.M. Produção de fungos entomopatogênicos. In: ALVES, S.B. (Ed.). Controle microbiano de insetos. 2.ed. Piracicaba: FEALQ, 1998. p.845-869.

BRAZNER, J.C.; ANDERSON, R.L. Ingestion and absorption of Bacillus thuringiensis subsp. israelensis by Gammarus lacustris in the laboratory. Applied and Environmental Microbioliology, v.55, p.1386-1390, 1986.

CASTRO, V.L.S.S.; JONSSON, C.M.; MELO, I.S.; NUNES, F.V. Avaliação de risco ecotoxicológico de Thichoderma stromaticum usado como biopesticida. Ecotoxicology and Environmental Restoration, v.4, p.18-24, 2001.

CAVICHIOLO, F. Efeito da vitamina C (Ácido Ascórbico) em alevinos de Tilápia do Nilo (Oreochomis niloticus). 2000. 48p. Dissertação (Centro de Ciências Agrárias) Universidade Estadual de Maringá, Maringá, 2000.

ESPÍRITO SANTO, H.M.V.; RESENDE, D.C.; LATINI, A.O. Estratégias comportamentais de espécies nativas de peixes em lagos naturais mediante a presença de espécies exóticas, bacia do Rio doce, Minas gerais. Disponível em: <http://www. mma.gov.br/port/sbf/invasoras/capa/docs/paineis/ estrateg_comport.pdf>. Acesso em: 20 out. 2007.

FERNANDES, M.N.; PERNA-MARTINS, S.A. Epithelial gill cells in the armored catfish Hypostomus CF plecostomus (Loricariidae). Revista Brasileira de Biologia, v.61, p.69-78, 2001.
FERREIRA, D.F. SisVar - programa estatístico. Versão 4.2 (Build 39). Lavras: Universidade Federal de Lavras, 2003.

FROMTLING, R.A.; KOSANKE, S.D.; JENSEN, J.M.; BULMER, G.S. Fatal Beauveria bassiana infection in a captive American alligator. Journal of the American Veterinary Medical Association, v.175, p.934-936, 1979.

GENTHNER F.J.; MIDDAUGH, D.P. Effects of Beauveria bassiana on embryos of the inland Silverside fish (Menidia beryllina). Applied and Environmental Microbiology, v.58, p.2840-2845, 1992.

GENTHENER, F.J.; MIDDAUGH, D.P. Nontarget testing of an insect control fungus: effects of Metarharizium anisopliae on developing embryos of the inland silverside fish Menidia beryllina. Diseases of Aquatic Organisms, v.22, p.163-171, 1995.

GENTHNER, F.J.; CRIPE, G.M.; CROSBY, D.J. Effect of Beauveria bassiana and its toxins on Mysidopsis bahia (Mysidacea). Archives of the Environmental Contamination and Toxicology, v.26, p.90-94, 1994.

HENKE, M.O.; HOOG, G.S.; GROSS,U.; ZIMMERMANN, G.; KRAEMER, D.; WEIG, M. Human deep tissue infection with an entomopathogenic Beauveria species. Journal of Clinical Microbiology, v.40, p.2698-2702, 2002.

JOBLING, M. Environmental biology of fishes. London: Chapman \& Hall, 1996. 455p.

JONSSON, C.M.; GENTHNER, F.J. Avaliação da potência de patogenicidade e toxicidade do fungo entomopatógeno Colletotrichum gloeosporioides isolado de Orthezia praelonga em duas espécies de crustáceos. Jaguariúna: Embrapa Meio Ambiente, 1997. 27p. (Boletim de Pesquisa n.1).

JONSSON, C.M.; MAIA, A.H. Protocolo avaliação de agentes microbianos de controle de pragas para registro como biopesticidas, III. Testes em organismos não-alvo do ambiente aquático: organismos zooplanctônicos, organismos fitoplanctônicos e vertebrados. Jaguariúna: Embrapa Meio Ambiente, 1999. 33p. (Documentos 11).

KERWIN, J.L.; DRITZ, D.A.; WASHINO R.K. Nonmammalian safety tests for Lagenidium giganteum (Oomycetes: Lagenidiales). Journal of Economic Entomology, v.81, p.158-171, 1988.

MIDDAUGH, D.P.; GENTHNER, F.J. Infectivity and teratogenicity of Beauveria bassiana in Menidia beryllina embryos. Archives of Environmental Contamination and Toxicology, v.27, p.95-102, 1994.

OLIVEIRA, C.R.R.; RODRIGUES, M.L.A.; SICILIANO, S.; ARAÚJO, J.V.; ANJOS, D.H.S.; BITTENCOURT, V.R.E.P. Passagem do fungo nematófago Monacrosporium thaumasium através do trato gastrointestinal de eqüinos. In: SIMPÓSIO DE CONTROLE BIOLÓGICO, 7., 2001, Poços de Caldas. Resumos. Poços de Caldas: 2001. p.349. 
OSÓRIO, S.; DE LA CÁMARA, R.; MONTESERIN, M.C.; GRANADOS, R.; ÕNA, F.; RODRIGUEZ-TUDELA, J.L.; CUENCA-ESTRELLA, M. Recurrent disseminated skin lesions due to Metarrhizium anisopliae in na adult with acute myelogenous leukemia. Journal of Clinical Microbiology, v.45, p.651-655, 2007.

PEREIRA, R.M.; ALVES, S.B.; REIS, P.R. Segurança no emprego de entomopatógenos. In: ALVES, S.B. (Ed.). Controle microbiano de insetos. 2.ed. Piracicaba: FEALQ, 1998. p.171-194.

REVANKAR, S.G.; SUTTON, D.A.; SANCHE, S.E.; RAO, J.; ZERVOS, M.; DASHTI, F.; RINALDI, M.G. Metarrhizium anisopliae as a cause of sinusitis in immunocompetent host. Journal of Clinical Microbiology, v.37, p.195-198, 1999.

ROMANO, L.A.; CUEVA, O.F. Lesiones histológicas atribuídas a toxicos em Odonthestes bonariensis (Curv. y Val., 1835) (Pisces Atherinidade). Revista de la Associación de Ciencias Naturales del Litoral, v.19, n.2, p.135, 1988.
SHADDUCK, J.A.; SINGER, S.; LAUSE, S. Lack of mammalian pathogenicity of entomocidal isolates of Bacillus sphaericus. Environmental Entomology, v.11, p.189192, 1980.

SIEGEL, J.P.; SHADDUCK, J.A. Mammalian safety of Bacillus thuringiensis var. israelensis. In: BARJAC, H.; SUTHERLAND, D.J. (Ed.). Bacterial control of mosquitoes and black flies: biochemistry, genetics, and applications of Bacillus thuringiensis var. israelensis and Bacillus sphaericus. New Jersey: Rutgers University Press, 1990. p.202-217.

WINKALER, E.U.; SILVA, A.G.; GALINDO, H.C.; MARTINEZ, C.B.R. Biomarcadores histológicos e fisiológicos para o monitoramento da saúde de peixes de Londrina, Estado do Paraná. Acta Scientiarum, v.23, p.507-514, 2001.

Recebido em 31/10/07

Aceito em 10/11/08 